\title{
Research priorities in support of ocean monitoring and forecasting at the Met Office
}

\author{
J. R. Siddorn, S. A. Good, C. M. Harris, H. W. Lewis, J. Maksymczuk, M. J. Martin, and A. Saulter \\ Met Office, Exeter, UK \\ Correspondence to: J. R. Siddorn (john.siddorn@metoffice.gov.uk)
}

Received: 16 September 2015 - Published in Ocean Sci. Discuss.: 5 November 2015

Revised: 4 January 2016 - Accepted: 7 January 2016 - Published: 4 February 2016

\begin{abstract}
Ocean monitoring and forecasting services are increasingly being used by a diverse community of public and commercial organizations. The Met Office, as the body responsible for severe weather prediction, has for many years been involved in providing forecasts of aspects of the marine environment. This paper describes how these have evolved to include a range of wave, surge, and ocean reanalysis, analysis, and forecasts services. To support these services, and to ensure they evolve to meet the demands of users and are based on the best available science, a number of scientific challenges need to be addressed. The paper goes on to summarize the key challenges, and highlights some priorities for the ocean monitoring and forecasting research group at the Met Office. There is a need to both develop the underpinning science of the modelling and data assimilation systems and to maximize the benefits from observations and other inputs to the systems. Systematic evaluation underpins this science, and also needs to be the focus of research.
\end{abstract}

\section{Introduction}

Operational ocean monitoring and forecasting services provide information to marine users that primarily support safe operations in the marine environment, but have also evolved to cater for, amongst others, marine security, commercial operations, licensing for marine operations, marine environmental monitoring and numerical weather prediction. Ocean services in support of blue and green growth are therefore already available, some for a number of years, and have evolved to meet a growing range of users needs. Observations alone cannot, without enormous investment, provide the spatial or temporal coverage required for a marine monitoring capability, and are limited to a subset of the parameters that are required. It is therefore clear that modelling, with the appropriate assimilation of good quality observations, of the physical environment, the marine chemistry and the lower trophic level marine biology, is required to support these user needs.

Early operational forecasts were implemented in the UK to respond to catastrophic surge events, such as the 1953 storm that resulted in a surge event killing several hundred people in the UK (Baxter, 2005). Surge forecasting services were subsequently implemented at the Met Office, and are a factor in ensuring that subsequent storms of comparable magnitude have not had the same catastrophic impact (Lewis, 2015). Wave models are used to forecast the sea state for mariners and commercial operators. They are also used in combination with surge modelling to forecast coastal flooding, to provide a well-established part of the armoury for predicting and monitoring extreme weather events.

More recently ocean forecast and monitoring services have expanded from solving essentially two-dimensional wave equations to include the fully three-dimensional state (hydrodynamics) of the ocean. This was driven initially by the Royal Navy in the 1990s, with their requirement to understand the depth-resolved currents (for diver operations, mine hunting, and vessel operations) and the depth varying density and optical properties (for submarine operations and detection). A number of other users have since started using ocean analysis and forecast services, including seasonal forecasting, which relies on daily high-quality ocean state analyses for initialization of their forecasts. The need has also expanded to include reanalysis of the marine environment, to provide information about the mean state, variability, and 
Table 1. The main Met Office marine analysis and prediction systems and their key characteristics. Please refer to the text for details.

\begin{tabular}{|c|c|c|c|c|c|c|c|c|}
\hline System & Domain & Latitude & Longitude & Resolution & Assimilation & Forcing & Ensemble & Cycle \\
\hline \multirow{2}{*}{ Waves } & European & 30 to 70 & -20 to 42 & $8 \mathrm{~km}$ & None & UM Global & None & $4 \times$ daily \\
\hline & Atlantic & -80 to 80 & $\begin{array}{l}\text { Bound by } \\
\text { continents }\end{array}$ & SMC 25-12-6 km & None & MOGREPS & 24 lagged & $2 \times$ daily \\
\hline \multirow[t]{5}{*}{ Ocean } & Global & -83 to 90 & -180 to 180 & $1 / 4^{\circ}(\sim 25 \mathrm{~km})$ & SST, T/S, SLA & UM Global & None & Daily \\
\hline & Med & 30 to 47.5 & -5.5 to 42 & $1 / 12^{\circ}(\sim 9 \mathrm{~km})$ & SST, T/S, SLA & UM Global & None & Daily \\
\hline & N Atlantic & 20 to 80 & -90 to 20 & $1 / 12^{\circ}(\sim 9 \mathrm{~km})$ & SST, T/S, SLA & UM Global & None & Daily \\
\hline & Indian & -25 to 31 & 33 to 106 & $1 / 12^{\circ}(\sim 9 \mathrm{~km})$ & SST, T/S, SLA & UM Global & None & Daily \\
\hline & NWS & 40 to 62 & -20 to 13 & $1 / 15^{\circ} \times 1 / 10^{\circ}(\sim 7 \mathrm{~km})$ & SST & UM Global & None & Daily \\
\hline
\end{tabular}

change for planning and monitoring purposes for a number of users.

Operational ocean services are still relatively immature and scientific innovation is required to improve their quality. Understanding the priorities for Ocean Forecasting Research is important at any time, but none more so than at the moment when fundamental changes in both the scientific capability and the user drive provide significant challenges and opportunities. The increasing emphasis on monitoring the marine environment under legislation such as the Marine Strategy Framework Directive (MSFD) is driving the need to monitor the marine environment at levels not presently achievable. MSFD requires that EU member states have a marine strategy in place by 2020 that defines how they intend to monitor their marine waters, and therefore ensure that they can maintain Good Environmental Status (GES). Alongside this statutory driver, other users of the marine environment also require good quality marine information, the most notable being the renewable and oil and gas industries which have huge infrastructure programmes in areas like the North Sea, and extending into deeper waters. To operate safely (and within the law) they require an understanding of the physical environment in which they are working, including the particularly challenging need to have accurate historical information about, and predictions of, currents.

This paper provides an overview of the operational ocean monitoring and forecasting services being provided by the Met Office that can, and do, provide underpinning information available to support maritime and marine sustainable growth. The critical investments in science to ensure that the services can improve and adapt to changing requirements are described.

\section{Met Office ocean monitoring and prediction systems}

The Met Office develops and operates a range of monitoring and prediction systems, which are described below, and summarized in Table 1.

\subsection{Surface waves}

The Met Office wave models are based on NCEP's WAVEWATCH III $^{\mathrm{TM}}$ (WWIII; Tolman, 2009, 2014). WWIII has recently adopted a community model status, enabling users to benefit from model developments implemented by numerous research groups worldwide. For example, in the present operational configurations run at the Met Office, model options to use a flavour of the WAve Model (WAM) source term physics (Saulter, 2015) and with a second-order propagation scheme (Li, 2008) have been selected.

Deterministic operational forecasts are based on a suite of three nested configurations. A global wave model at approximately $35 \mathrm{~km}$ resolution is run four times daily, alternating between forecasting 2 days and 5 days ahead. This provides boundary conditions for a European wave model at approximately $8 \mathrm{~km}$ resolution, running a similar cycle, and a UK waters model at $4 \mathrm{~km}$ resolution, which also runs four times daily but is limited to 2-day forecasts. Although WWIII allows a two-way nesting capability, we presently only provide one-way boundary conditions. At present, all configurations are forced by the Met Office global atmospheric model, which has a horizontal resolution of the order of $17 \mathrm{~km}$. The Met Office has also built and run higher resolution wave models for coastal applications on an ad hoc basis using the Simulating WAves Nearshore (SWAN) model. For example, an application was built and run for Weymouth Bay as part of the Met Office's support for the London 2012 Olympics (Golding et al., 2014). 
In the next 12 months, the Met Office expects to make three enhancements to this system. The first is the implementation of a refined grid wave model, in which the wave model comprises cells of different resolutions so that highresolutions can be applied near the coast whilst retaining more computationally efficient larger cells in deeper open waters. The advantage of adopting this method is to reduce the need to maintain multiple nested model configurations. The grid refinement method developed at the Met Office uses the spherical multiple-cell (SMC) grid ( $\mathrm{Li}, 2011)$ and will first be implemented as a global wave model ( $\mathrm{Li}, 2012$; $\mathrm{Li}$ and Saulter, 2014). Li and Saulter (2014) demonstrated that, for an experiment where global and regional wave models are forced using the same wind fields, a global SMC model is capable of achieving comparable levels of skill to a nested modelling system in which the high-resolution model cells and SMC coastal cells are similarly scaled. In such cases the SMC model should be much more efficient than the nested model since (a) no sea areas are duplicated in the SMC model (in a one-way nested system the area of the regional model will be represented in both global and regional systems, whilst for a two-way model a boundary stencil area will be replicated in both models) and (b) the use of grid refinement means that open waters in the regional-scale model can be represented by coarser cells in the SMC model grid.

An SMC grid model for the Atlantic has already been implemented as a wave ensemble prediction system (wave EPS; Bunney and Saulter, 2015). Forecasts from the system are being trialled with a number of users in order to establish requirements for probabilistic decision-making data products. As a forced-dissipative system, the spread in wave forecast errors can be primarily simulated using the spread derived in wind data from an atmospheric ensemble. In this case, the Atlantic wave model is driven using members from the Met Office Global atmospheric ensemble MOGREPS-G (Bowler et al., 2008), with horizontal resolution of approximately $30 \mathrm{~km}$.

For waters around the UK, it is recognized that a high degree of variability in the oceanic conditions, particularly associated with the tides, will introduce variability in the wave field. A version of the UK waters wave model, which has been one-way coupled to currents from the Met Office's northwest European shelf seas model, is presently undergoing verification trials and will be made operational during 2016.

\subsection{Storm surges}

Tide-surge models are run in real time as part of the forecast suite of models. Results are used by the joint Environment Agency/Met Office Flood Forecasting Centre, together with data from the National Tide Gauge Network, for coastal flood warning in England and Wales.

The first operational surge forecasts were run in 1978 using coarse-grid surge and atmospheric models. The present system is built around a two-dimensional barotropic ocean model (Flather, 1994) with configurations comprising a $12 \mathrm{~km}$ UK continental shelf model (CS3X), with refinements to 4 and $1 \mathrm{~km}$ in order to provide useful predictions in the complex regime of the Bristol Channel and Severn Estuary.

A deterministic surge model suite comprising CS3X, Bristol Channel, and Severn Estuary models is run 4 times daily, forced by wind and surface-pressure data from the Met Office's global atmospheric model. CS3X is also run as an EPS forced by MOGREPS-G. Similar to waves, uncertainty in the surge forecast is primarily influenced by uncertainty in the atmospheric forecast, such that good probabilistic performance can be achieved through perturbing surge-EPS members purely by the forcing atmospheric-EPS data (Flowerdew et al., 2010).

\subsection{Operational Sea Surface Temperature and Sea Ice Analysis}

The Operational Sea surface Temperature and sea Ice Analysis (OSTIA; Donlon et al., 2012b) system was developed at the Met Office for use in numerical weather prediction and ocean forecasting systems. It is run in near-real time on a daily basis. OSTIA produces a global field of sea surface temperature (SST) (free of diurnal variability) every day on a $1 / 20^{\circ}(\sim 6 \mathrm{~km})$ grid. The system uses SST input data from satellite measurements together with in situ data and a sea ice concentration product. Data assimilation methods are used to combine the different SST input data with a background field, taking into account estimates of the observational uncertainty, to produce a gridded analysis. The background field is a SST forecast made by persisting anomalies from the previous day's analysis with some relaxation towards climatology. An uncertainty estimate is provided, giving each SST value an associated uncertainty. OSTIA is widely used, particularly in numerical weather prediction centres (including the Met Office and ECMWF), where it is used as a lower boundary condition in weather forecast models. The OSTIA system is continually being developed and improved. For example, in November 2011, lake surface water temperatures were added for 248 lakes across the globe (Fiedler et al., 2014). The OSTIA analysis and analyses produced by various institutes around the world are used to create the Group for High-Resolution (GHRSST) Multi-Product Ensemble (GMPE) product for the global ocean (Martin et al., 2012). The analyses are regridded onto a common $1 / 4^{\circ}$ grid and the ensemble mean and standard deviation are calculated. This provides a mechanism to compare analyses and potentially facilitate their development.

The OSTIA processing system is also used to produce reprocessed products of global SST over the satellite era (Roberts-Jones et al., 2012), Most recently, as part of the European Space Agency (ESA) SST Climate Change Initiative (CCI), the OSTIA system was developed and a reprocessing based on ESA SST CCI input satellite data was performed. 
Aimed at climate research users, this reprocessing covers late 1991-2010 (Merchant et al., 2014).

A new diurnal analysis has recently been developed, which produces hourly skin SST fields on a $1 / 4^{\circ}$ grid. It is generated by combining the OSTIA foundation SST analysis with models of the layer of water subjected to solar heating (the warm layer) and the layer that loses heat through emission of longwave radiation (the cool skin). Satellite SSTs are assimilated into the warm layer model. This diurnal product, together with OSTIA foundation SSTs, the GMPE product, and a reprocessing are made available through the Copernicus Marine Environment Monitoring Service (CMEMS), which are available from http://marine.copernicus.eu. The ESA SST CCI analyses are available from http://www.neodc.rl.ac.uk/.

\subsection{Forecasting Ocean Assimilation Model}

The Met Office provides three-dimensional predictions of the ocean state using the Forecasting Ocean Assimilation Model (FOAM) suite of systems. These include global and shelf seas implementations, and as well as the physical environment the marine biogeochemistry and lower trophic level plankton are simulated for shelf seas.

The primary shelf seas region of focus is the European North West Shelf, which includes the continental shelf waters of the United Kingdom and neighbouring countries. A global capability is also required, with basin-scale regions at higher resolutions in the North Atlantic, Mediterranean, and Indian Ocean.

Since early this century the Met Office, in collaboration (in particular, but not exclusively) with the National Oceanography Centre (NOC) and Plymouth Marine Laboratory (PML), have developed and delivered operational services from ocean models coupled to marine biogeochemistry models. Siddorn et al. (2007) describes the first system, to our knowledge, to operationally produce analyses and forecasts of the hydrodynamics and biogeochemistry of shelf environments. It was implemented primarily for the use of the Royal Navy, but there is also significant interest in, and use of, this type of service from other agencies responsible for marine monitoring and response activities.

The shelf seas forecasting was transitioned to use the Nucleus for European Modelling of teh Ocean (NEMO) (Madec, 2008), which is also used for the global- and basinscale forecast systems. This allowed, amongst other things, a data assimilation capability already implemented for the deep-water systems to be implemented efficiently in the shelf seas systems. At present, only surface-temperature data are assimilated in Met Office shelf seas systems. The short time and space scales in the shelf seas, with respect to the data availability, make assimilating data here a particular challenge. However, progress is being made and assimilation of subsurface temperature and salinity data and sea surface height data (King and Martin, 2013) will become operationally viable within the next couple of years. Research on ocean colour assimilation has also shown promise, although considerably more development is required before this is ready for operational implementation.

O'Dea et al. (2012) describes the operational implementation of the FOAM AMM7 (Atlantic Margin Model) at $\sim 7 \mathrm{~km}$ resolution, the successor to the forecasting system detailed in Siddorn et al. (2007). The model has now been consistently shown to be as good as or better than its predecessor, and was for example shown by O'Neill et al. (2012) to outperform a significantly higher resolution equivalent for the Liverpool Bay region. Within the Met Office the success of the NEMO-based system led to implementations in other regions, for example in the Persian Gulf region (Hyder et al., 2012). The development work done in the North-West European Shelf region provided the science starting point for this work. The Gulf is an interesting region dynamically, with the Straits of Hormuz acting as the natural boundary between the shallow and tidal Persian Gulf waters and the Indian Ocean.

Storkey et al. (2010) described the first implementation of an operational forecasting system using NEMO at the Met Office. The primary configuration implemented was a global system based upon the configuration developed at Mercator Océan, using an 1/4 ${ }^{\circ}$ ORCA grid (Drévillon et al., 2008), a tripolar, curvilinear discretization that allows the poles to be placed over land and gives enhanced resolution at high latitudes. Three other basin-scale configurations for regions of particular user interest (the Mediterranean, the North Atlantic, and the Indian Ocean) were also implemented on regular lat-long grids (rotated in the case of the North Atlantic model $)$ at a higher $\left(1 / 12^{\circ}\right)$ resolution, giving a suite of forecast systems that is eddy permitting over the globe and eddy resolving in key basins.

\section{Science challenges and priorities}

\subsection{Observations}

The importance of observations to operational ocean forecasting cannot be overstated. They provide the basis on which process understanding is acquired, and therefore underpin fundamental model and system development. They are also needed as the basis for understanding the skill of monitoring and prediction systems. Timeliness requirements for observations for model/system validation, which is done on simulations of the recent past and can therefore take advantage of research data and observations that have been through a rigorous quality control process, differ to verification that requires observations to be available within days if not hours of collection. Data assimilation also requires observations and, for forecast simulations, also needs them within a short period of the validity time. For both verification and assimilation it is therefore critical that the data are timely and have good metadata such as quality flags and well-described error characteristics. 
The space and time sampling of the ocean is far from optimal, and one of the challenges for ocean services is to make the best use of the available observations. It is therefore a priority that best use is made of available data sets. Current verification is presently not done effectively, and more use could be made (for example) of global velocity observations from drifter displacements. Acoustic Doppler Current Profiler (ADCP) data are still difficult to work with in operational settings, and more should be done to ensure they are used as effectively as possible. Gliders and other autonomous vehicles are becoming increasingly prevalent, and available in real time. This has the potential to make a significant difference to the sub-surface data available, especially in marginal seas, if the data become readily available. Argo profiling floats have made a significant difference to the sampling in the open ocean of subsurface temperature and salinity, and the use of Argo is already well established for data assimilation as well as verification and validation in our forecasting systems. The Argo programme will continue to evolve, and making the best use of new Argo data sets, for example biological or near-surface data, will ensure our systems continue to improve.

Satellite data are a key component of the observing system as they can provide relatively good spatial coverage and tend to be delivered to operational centres quickly after collection. The sensors and algorithms have generally relatively well-described error characteristics, and the missions are well known in advance so can be planned for. The Sentinel-3 satellites due to be launched later this year and in future years will provide high-quality sea-surface topography, sea-surface temperature and ocean colour, and have been designed specifically for support of ocean forecasting systems. However, satellites can only provide measurements of the surface of the ocean, cover a relatively limited part of the desirable parameter space, and can often be at lower accuracy than either in situ observations or at times the models themselves. For example, Janssen et al. (2007) showed observation errors in significant wave height data from the ERS-2 altimeter to only be a few percent lower than the errors from a global wave model.

A well-designed in situ data network is therefore also critical for the success of operational oceanography. Collecting data at sea is a time-consuming and costly business and there is never therefore likely to be the sort of observational coverage from traditional collection methods that we would like. However, there are a number of things that could be done to improve the current situation. The most likely to show impact in the short term is to ensure that data that are already collected are as widely (and quickly) available as possible. This is not a trivial task, given the difficulties in ensuring data are distributed with suitable quality control and metadata. It can also be complicated by intellectual property rights and commercial constraints. OceanObs'09 convened in Venice in 2009 to develop a "common vision for the provision of routine and sustained global information on the marine envi- ronment" and produced a conference statement (Conference Statement, 2010) that highlighted the need for systematic, sustained, real-time observations collection. The conference summary (Fischer et al., 2010) highlights the key investments needed to meet societal needs for an ocean-observing system. The more the diverse communities involved in marine observation collection can work together to agree on protocols for quality controlling and onwards distribution of their data the more benefit can be accrued from it, not least from improvements in the ocean forecasting and monitoring services.

Other data sets are becoming available that could, with effort, make a major difference. Satellite salinity data from Soil Moisture Ocean Salinity (SMOS) and Aquarius have been demonstrated to provide some useful information (Martin, 2015), but improvements still need to be made to their biases for them to meet their potential. More widespread use of voluntary observers has significant potential. Sensors on fishing gear have shown significant potential, but are generally still at the trialling stage and do not as yet deliver significant quantities of data. High Frequency (HF) Radar has the potential to provide a step change in the monitoring of currents in coastal waters, but coverage is limited in many regions, notably in the North-West European Shelf.

Making optimal use of the present observing systems and technologies that are available or likely to become available in the near future will allow the ocean forecasting community to make good progress. However, that is not to say that the observing system is optimal for the purposes of ocean forecasting. A number of parameters are poorly observed, particularly salinity, currents, and biogeochemical parameters. The evolving services will also put greater demands on the observation network, with more complete Earth prediction systems increasing the range of observations which will be required in real time. The drive to provide ocean forecasting services at eddy-resolving scales globally and in shelf seas also means the requirements for the spatial and temporal frequency of the observational network to constrain the model systems is increasing. The ocean forecasting community must ensure that these needs are well articulated through the use, for example, of Observing System Experiments (OSEs) to demonstrate the impact of existing observation types and Observing System Simulation Experiments (OSSEs) to ensure that the requirements for new observing networks are well defined.

In summary, as a priority the ocean forecasting community must (a) make best use of available data, (b) support data collectors in making their data available in a timely and usable way, (c) support the investment in technologies already close to operational readiness and ensure they are pulled through to demonstrate impacts, (d) demonstrate the impact of the present observing systems, and (e) articulate the evolving needs for a new or updated observing system. 


\subsection{Ocean modelling}

Progress is needed to ensure models used to provide ocean services are of sufficient quality to provide the information required. Producing operational simulations that have sufficient skill requires model developers to improve numerical schemes and parameterizations that prescribe the inputs to the system.

Ocean models (including biogeochemistry models) are still at a level of maturity whereby significant improvements to skill can be found from improving their process representation. Process improvements are important and will continue to improve the systems, but require significant investment of science expertise to have a significant impact. However, improving atmospheric, riverine, or lateral boundary inputs is often overlooked as an important driver for improved skill, and can give substantial benefits for relatively minor investments of time and computing power. Unfortunately, there is a limit to the availability of good quality input data.

A number of processes are not fully represented in ocean models, either as the computational cost is considered to outweigh the benefit or the complexity added by including the processes is too onerous. Examples include representing tides in global ocean models and modelling the interactions between the surface ocean and surface waves, which are both represented by relatively simple empirical relationships. As we improve our modelling capability, we need to consider where increasing complexity of our systems can provide benefits by replacing implicit or missing processes with wellposed algorithms or additional models/sub-models. This can be time-consuming and also often comes with significant additional computational cost implications, especially when full coupling to additional components of the Earth system. Increased complexity systems can often be helpful in informing the model development process even if not incorporated as part of the final production solution.

\subsubsection{Vertical mixing}

Errors in vertical mixing tend to be amongst the most significant issues for ocean forecasting problems, both because of the short time and space scales on which surface forcing and the dynamic processes in the mixed layer operate and because of the impact of errors in exchange across the thermocline can have upon water masses. This is a particular problem for any coupled forecasting systems where the surface properties of the ocean are unconstrained by the atmospheric model forcing and errors can feedback to the atmosphere causing rapidly growing biases. Improving upon vertical mixing properties in ocean models is a priority for the ocean forecasting community. Present schemes are often dominated by pragmatic tuning options that dominate the mixing and result in mixing schemes that poorly represent the real processes. NEMO for example relies on both a constant background minimum viscosity and diffusivity and an additional wind-related penetration of turbulent kinetic energy through the mixed layer due to internal and inertial waves to compensate for a lack of explicitly included processes like internal wave breaking or shear spiking at the base of the thermocline. The exchange of scalar properties from the surface to deep waters and vice versa is therefore dominated by a number of tunable parameters, which have limited traceability to the true physical processes.

The OSMOSIS (Belcher et al., 2012) project is seeking to redress this problem by incorporating a more realistic set of processes into a mixed layer model that will couple to a more traditional two-equation model below the mixed layer. The project is still at the stage of developing schemes in idealized settings. There is still more to be done to move from the idealized to the real application, for example to address how the OSMOSIS mixed layer model will behave under ice and in shelf seas where the bottom and surface-boundary layers can overlap. However, in the medium term this has the potential to redress some of the shortcomings in this area. As our understanding and parameterization of mixing processes improves we will increasingly be adding new explicit terms for mixing into our models. This further highlights the issue of spurious numerical mixing, especially for relatively quiescent regions.

\subsubsection{Numerics and grids}

Alignment of the vertical coordinate with isopycnals is important in reducing this spurious mixing, and a suitable choice of vertical coordinates (e.g. Siddorn and Furner, 2013) is key to this. However, short of working in an isopycnic framework, which gives rise to other complications, a nonadaptive coordinate cannot eliminate the impact of undulating isopycnals. Leclair and Madec (2011) developed an arbitrary Lagrangian-Eulerian (ALE) capability for the NEMO model (termed the $\tilde{z}$ coordinate) that applies the Lagrangian component (i.e. grid adaptation) in response to fast moving waves. This neatly allows the model to limit the amount of adaptation required whilst removing the primary source of spurious vertical mixing. Petersen et al. (2015) described the impact of a range of vertical coordinates, including fully ALE and the $\widetilde{z}$ subset of ALE and concluded that the use these coordinates worked well at reducing spurious mixing under many scenarios. These formulations should be introduced into operational configurations once they are sufficiently mature. Improving the advection/diffusion schemes is very much business as usual for the ocean model development community and will undoubtedly continue. However, the numerical properties of any modelling framework are inextricably tied to the numerical framework within which they are coded. Work being done on grids for atmosphere modelling, where it is a pressing problem, is providing insight into the optimal approach to take. For example, there is the US MPAS project (Ringler et al., 2013) and the UK's GungHo project (Thuburn et al., 2015) both of which are, 
or have, developed new grid frameworks and appropriate numerical schemes that have improved properties for geophysical modelling (Cotter and Thuburn, 2014). There may be a significant benefit for the ocean modelling community to follow the lead of these projects, but it should be noted one of the key drivers for these activities is the polar singularity issue, which in ocean models can be hidden through placing poles over land. The present consensus is that the most promising numerical approach probably lies in C-grid finite volume methods like those implemented in MPAS rather than finite element-based discretizations (Danilov, 2013) which have been tried for the low aspect-ratio ocean problems but without great success to date. As most ocean models presently used are based upon C-grid finite-difference methods, the pressure for change is relatively low in the ocean community. However, as computing infrastructures change the benefits to move to unstructured, finite volume or element solutions may increase.

\subsubsection{Shelf seas processes}

Shelf sea environments present a number of challenges to modellers. First, they are dynamic regions where a range of processes need to be represented if realistic simulations are to be achieved. The wind- and buoyancy-driven residual circulation is superimposed upon the tidal circulation that is a function of the local and far-field forcing, and has such a major impact upon these regions. The difficulty in representing the relatively poorly understood dynamics of shelf slopes, where mesoscale and submesoscale processes can have a significant impact, means cross-shelf exchanges can be particularly difficult to model. This is compounded by enhanced numerical errors in regions where the model grid is not aligned well with isopycnals. Small-scale (turbulent) processes are important in determining exchanges across interfaces, most notably vertically in seasonally and tidally stratified waters but also horizontally, for example in determining the horizontal extent of the influence of freshwater discharges as the freshwater is mixed with adjacent waters by baroclinic instabilities.

Shelf sea environments also present particular challenges in that they are significantly influenced by the deep ocean, land, sea-bed, and air boundaries. Therefore, not only do the relevant dynamical processes need to be well represented, but also the inputs to the system need to be well specified. Poor river sources of freshwater can have a dramatic effect upon the model solution. Good quality bathymetry and coastlines still remain a limitation, exacerbated by the difficulty in defining a roughness length in an environment that not only has highly spatially variable bottom types that are poorly monitored but also, may have rapidly evolving changes to the bed morphology. Air-sea exchange parameterizations tend to be based upon empirical formulations derived from flux measurement campaigns, which may not be entirely representative of the marine environments being modelled. The atmospheric models used to provide atmospheric boundary information are imperfect and primarily tuned to give the best solutions over land where the dominant societal impact is to be found.

\subsubsection{Resolution}

There are fundamental scales in the ocean that need to be considered when deciding at which resolution to develop model configurations. At the smallest scales turbulent motions are clearly not resolvable and so these are parameterized, in the vertical using turbulence closure models and in the horizontal through diffusion operators. In the recent past mesoscale processes have not been resolved, and so methods for parameterising the impacts of mesoscale motions upon vertical restratification have been included in global models (e.g. Gent and McWilliams, 1990). We are now entering a period when computing power is such that operational modelling systems are under development at resolutions that can in the main resolve the mesoscale (of the order $1 / 15^{\circ}$ globally and $1 \mathrm{~km}$ in mid-latitude shelf regions). At these resolutions the challenge is to parameterize turbulent motions at the (smaller) grid scales, including sub-mesoscale eddies and filaments.

\subsubsection{Marine biogeochemistry}

Increasingly there is a drive for forecasting and monitoring of the whole Earth system, including the marine biogeochemistry. Presently, the skill of biogeochemistry models is limited for forecasting bloom events. Allen et al. (2010) gives an interesting oversight of the challenges confronting the developers of biogeochemistry systems. The biogeochemistry model accentuates physical model errors, and therefore particular attention needs to be paid to the hydrodynamic modelling framework (including assimilation) errors in the context of their implications for biological function. These seem particularly pressing in the vertical. We are still at the stage in the biological modelling community of trying to understand what modelling tools give the best trade off between complexity (costly, but potentially overfitted) and simplicity (inexpensive, but missing some key processes). Even in any given model structure, the parameterizations are not necessarily well described given a lack of understanding of the processes and data to constrain them. Developing well-posed biogeochemistry models is therefore still an area that needs active research.

\subsection{Waves and surge}

Although wave forecasting services have a longer track record of operational use than their ocean counterparts, continuing enhancements in the parameterizations and numerical methods underpinning spectral wave models (as summarized by the WISE group 2007; Tolman et al., 2013; and in proceedings of the ECMWF Workshop on Ocean Waves, 
2012) present numerous opportunities to improve both skill and utilization of wave forecasts. Recent years have seen a number of refinements to the source term physics schemes used to represent the growth and dissipation of wind-sea energy. In particular, work by Ardhuin et al. (2010) and Babanin (2011), amongst others, has begun the process of explicitly parameterizing wave energy dissipation in wave models, rather than treating this term as a method to achieve energy closure. An improved representation of wave dissipation will be crucial to more accurately representing the transfer of momentum from the atmosphere-wave boundary layer into the ocean within coupled models. Increased computational resources and numerical scheme developments (e.g. Tolman, 2012) indicate a longer-term potential to improve on the nonlinear wave-wave interaction parameterization source term, which, for reasons of computational efficiency, has long used the Discrete Interaction Approximation of Hasselmann et al. (1985). For any change to the source terms, moving to an operational model that better represents one source term generally requires review and re-tuning of the other terms, in order to derive the best overall representation of day to day wave spectrum evolution by the forecast model. The challenge for an operational wave forecasting group, such as the one at the Met Office, is in identifying the value of these improvements in the background science and when they can be practically applied within an operational computing framework that has finite resources and strict release timing deadlines.

Whilst source terms improve, it remains the case that the key determinant for wave forecast skill is the quality of the wind forcing applied to the model (Cavaleri and Bertotti, 2006; Janssen, 2008) and, where appropriate, inclusion of variations in the current and depth regimes affecting wave energy propagation and wave steepness. Regarding the latter processes, UK waters are subject to strong tidal regimes and depth variations, such that wave observations in the coastal zone often exhibit a significant tidal signature. Improving the wave model's representation of tidal processes is presently a priority area for research. In principle, incorporating (at least) ocean current fields in global wave models in order to properly represent wave field evolution in known strong current regions, such as the Gulf Stream, Agulhas, and Kuroshio, should be a next stage in development, although generic concerns over the quality of ocean model forecast fields and challenges in demonstrating the value of this coupling (due to sparseness in wave observations) suggests that near-future developments may remain restricted to regional systems. The development of increasingly high-resolution atmospheric models, which explicitly represent convective processes, may also lead to challenges in future. In such models a high level of detail can be developed in the wind field, but not necessarily placed correctly in time and space, presenting a particular problem for site-specific forecasts due to double penalty effects. How these effects play out over the ocean needs to be assessed, since wave and ocean mod- els generally smooth wind field inputs, potentially leading to a reduction of double penalty effects, whilst coastal zone wind representation should be improved by using a higherresolution description of the land-sea boundary.

In many cases, improvements to wave model science lead to small incremental benefits in terms of the most commonly used wave model data, i.e. forecasts of significant wave height derived from the overall wave spectrum. However, the bigger picture is that many recent science and model resolution changes ought to lead to a significant expansion in the geographic scope and range of wave forecast services that can be provided to users. For example, the development of the SMC grid models run by the Met Office is aimed at providing wave forecasts that correctly represent the near-coastal zone without the requirement to run and maintain multiple high-resolution nested coastal wave models. This development is important in terms of service reach, as the coastal zone has a far higher number of marine users than the open seas. As well as improving the bulk wave energy prediction represented by significant wave height, recent source term improvements have led to a verifiable improvement in representation of the wave spectrum (e.g. Bidlot et al., 2005; Ardhuin et al., 2010). This means that forecasters should be able to offer a wider range of wave forecasts describing characteristics of the sea-state additional to significant wave height, for example wave steepness (Savina and Lefevre, 2004; Niclasen et al., 2010), whether seas are confused or regular due to the presence or otherwise of multiple wave components comprising wind-sea and swells (Savina and Lefevre, 2004; Kohno, 2013), and, potentially, the risk of occurrence of so-called rogue or freak waves (Janssen and Bidlot, 2009). Development of ensemble prediction systems also expands the list of potential products that can be developed dependent on a user's preference to receive deterministic or more risk-based information. A significant proportion of the operational model development team's task is, therefore, to demonstrate and advise marine forecasters on the value of and methods to exploit an increasingly rich data set of good quality wave parameters.

In a similar vein, a key challenge for improvement of both modelling and utilization of parameters associated with storm surges is to better combine the effects of both surge and wave when issuing flood forecast advice. In terms of background science, two-way feedbacks exist between surface waves and tide plus surge in shallow waters. Brown and Wolf (2009) demonstrated that these effects modify both the wave field and the surge, indicating the need both for coupling wave and surge models and applying wind stress to the surge model via the waves (e.g. a modification to the wind stress that accounts for the amount of energy being transferred from the atmosphere to the wave field). Generally, UK storm-surge modelling has concentrated on large-scale (basin) surges, which are driven by synoptic-scale meteorology. However, resolution improvements enabling an understanding of variability introduced on the convective scale 
may lead to the addition of useful detail to the forecast surge and wave forecast, for example in indicating smaller-scale surges sometimes referred to as meteotsunamis (e.g. Tappin et al., 2013). From the forecasting point of view, understanding details of the wave field alongside high tide plus surge conditions should enable forecasts to add extra detail when identifying areas of coastline at particular risk. This is since the degree of wave energy reaching the coast will be highly dependent on the difference in angles between waves offshore and the alignment of the coast, plus the likelihood of waves shoaling and refracting in the nearshore. Both of these processes are influenced by wave period, leading to a problem with many degrees of freedom. Ongoing work at the Met Office includes a dialogue between flood forecasters and the modelling team on how best to work with a combination of both surge and wave information within a probabilistic forecasting framework.

\subsection{Quantifying uncertainty}

Ensemble predictions are increasingly being seen as a priority for future generations of ocean forecasting systems. Ensembles are already routinely, and widely, being produced for surface-wave and storm-surge systems, with the spread in the ensemble generated by fluxes from an atmospheric EPS (e.g. Bowler et al., 2008). This provides reasonable spread for surface-wave and storm-surge systems, where the solution is tightly coupled to the forcing. However, this is not likely to be sufficient in full ocean simulations, where the initial state and internal ocean dynamics are also important components of the uncertainty. Forcing perturbations (e.g. from a coupled atmosphere) may induce some spread in the near-surface ocean variables (e.g. Sakov et al., 2012; Pinardi et al., 2011) but are unlikely to be enough to produce the correct spread for the deeper ocean. In order for the ensemble to be useful for ocean forecasting, perturbations to the ocean initial conditions and internal dynamics are therefore required.

\subsection{Coupled prediction}

A key driver for the ocean forecasting community is the growing interest in coupled ocean-atmosphere forecasting, which has the potential to better represent some of the interface exchanges. The importance of air-sea interaction in both the modelling of the ocean and atmosphere has been recognized for many years. The timescales on which these interactions have traditionally been considered important has limited the use of coupled models to studies or prediction systems for monthly and longer timescales and while the need to represent feedbacks between different components of the environment is well understood and mature for climate prediction, the use of coupled approaches is not as well developed on shorter timescales. However, as weather models increase in resolution, and the focus on hazards predic- tion increases, the potential for air-land-sea-ice-waves coupling systems is increasingly driving research activity. There have been several vision papers (e.g. Brunet et al., 2010) and workshops relevant to this area, in which the importance of coupling is becoming increasingly recognized for weather timescales. The need to accelerate progress in Earth System prediction across all scales (climate and weather, global and local) was discussed by Shapiro et al. (2010), and this message was strongly reinforced during the 2014 World Meteorological Society's World Weather Research Programme (WMO WWRP) Open Science Conference in Montreal.

The Global Ocean DAta Assimilation Experiment (GODAE) OceanView (GOV) Science Team, recognizing the need to explore the potential benefit to both oceanic and atmospheric forecasting, formed the Short-to Medium-Range Coupled Prediction Task Team. Given the obvious need to join up efforts with other communities, a link with the Working Group for Numerical Experimentation (WGNE) was formed and a joint GOV-WGNE workshop was held in March 2013 to discuss the status, plans, and challenges of coupled forecasting. The progress made by the communities involved in the Short to Medium Range Coupled Prediction Task Team (SMRCP-TT), since its inception on understanding coupled modelling, its challenges and benefits, and in building coupled systems, is detailed in Brassington et al. (2015). One of the key regions where coupled oceanair interactions are of importance is in the tropics, and recent work has demonstrated that, in addition to improved verification against various tropical ocean and atmospheric metrics, Madden-Julian oscillation (MJO) predictions are in some instances superior in coupled hindcasts (Shelly et al, 2014). Also important for the Met Office, in its role as the UK's weather service, is the formation and/or evolution of extra-tropical storms, the ability to simulate land-sea-breeze circulation and the formation of coastal fog, all of which can be expected to be improved by coupled modelling.

The Met Office strategy for both weather and ocean forecasting is to focus upon a two system approach, one global and one for the UK. The coupling activities follow the same approach, and this paper outlines the rationale and benefits for, and recent progress in developing, each system separately. Given the scientific and technical expertise on coupled modelling in the Met Office, and the strategy for seamless prediction that is increasingly bringing the weather and climate systems in closer alignment, we are well placed to make (and are already making) significant progress in coupled modelling on weather timescales. Nonetheless, the move to coupled forecasting presents significant technical, scientific, and resourcing challenges which are discussed below.

Regional systems are being developed around the world, one of the most advanced being the UK Environmental Prediction system, a joint NERC and Met Office activity led from the Ocean Forecasting group at the Met Office. A global coupled system is already delivering ocean forecasts opera- 
tionally to the CMEMS (http://marine.copernicus.eu). These systems are described below.

\subsubsection{Regional systems}

For regional high-resolution prediction, there is already evidence of the benefit of coupled prediction for improving weather forecast skill. For example, coupled atmosphereice-ocean forecasts are now operational at the Canadian Meteorological Centre for the Gulf of St Lawrence region in Canada, with evaluation demonstrating significant improvement in the skill of both atmospheric and ice forecasts (Smith et al., 2013 and others). A key component of this activity was the design and development of a flexible and collaborative modelling framework for coupled land surface and hydrological models (Pietroniro et al., 2007; Deacu et al., 2012). This enabled better understanding of the behaviour of different land surface models and objective testing of different schemes for producing ensemble streamflow forecasts to improve the representation and accuracy of the regional water budget.

Coupled regional prediction systems have also been applied in research mode to improve the representation of airsea interactions on Bora winds over the Adriatic (e.g. Pullen et al., 2006), on the evolution of Mediterranean storms (e.g. Renault et al., 2012), on hurricane formation and development (e.g. Warner et al., 2010) and on suppressing the urban heat island effect in New York (e.g. Pullen et al., 2007). The challenge now is to realize the potential of integrated regional coupled prediction in the UK context, and a robust flexible coupling strategy over the short-medium term is a key requirement to underpin this research activity.

The Met Office, the Centre for Ecology \& Hydrology, the National Oceanography Centre, and Plymouth Marine Laboratory are now working with others to accelerate research progress in developing the foundations of a coupled highresolution UK forecast system that links together predictions of the atmosphere, coastal ocean, land surface processes and hydrology. A prototype project is now in progress to develop and evaluate a first look system. This work has needed to develop and test new ocean and atmosphere (and land surface) configurations on a new domain - extending the atmosphere model domain relative to the operational configuration to provide sufficient coverage across the North-West Shelf and increasing the horizontal resolution of the ocean component relative to the AMM7 operational configuration to be comparable with the atmospheric resolution. Initial evaluation of the first coupled atmosphere-ocean system is currently under way. The immediate development priority is to add a wave model component to begin to represent and evaluate threeway interactions acting on a variety of timescales between ocean, atmosphere, and the surface-wave field.

\subsubsection{Global systems}

The leading order impact of including an interactive ocean model as part of a coupled operational numerical weather prediction (NWP) system is that the atmosphere will see a more realistic evolving SST during the forecast period. It is therefore expected that the main benefits will be in regions where there is a large diurnal SST range (particularly the tropics) or where ocean surface temperatures can change rapidly due to large heat fluxes or strong ocean mixing processes. Previous work (e.g. Kim et al., 2010) has shown that permitting high-frequency SST variability (by coupling atmosphere and ocean components at least every few hours) has significant benefits in the tropics by allowing for a better phase relationship between SSTs and convection, and increasing the ability of models to forecast the spatial and temporal evolution of the MJO. As mentioned above indications of improved MJO predictions have already been seen in Met Office coupled systems (Shelly et al., 2014). There is also evidence that mid-latitude storm generation and evolution can be better predicted in a forecast model with an interactive ocean and atmosphere. Such benefits are expected to be more fully realized once the ocean model resolution is high enough to provide a detailed representation of the sharp SST gradients (associated with, for example, eddies), which can then strongly influence the atmospheric boundary layer. A number of studies (e.g. Janssen et al., 2013) have shown that using a coupled system has an impact on the evolution of slow moving tropical cyclones due to cooling of SSTs as heat is removed from the surface ocean. This is expected to correctly reduce the tendency of atmosphere-only models to otherwise over-develop such systems, particularly as the resolution increases.

Development towards using global coupled atmosphereland-ocean-sea-ice prediction, including coupled data assimilation, for operational short-range forecasts at the Met Office continues. The coupled system is based upon the Global Coupled system (GC2) being developed for applications across all timescales (Williams et al., 2015) and therefore benefits from the significant development across the Met Office over the last decade for monthly, seasonal, and climate coupled applications. A consistent atmosphere configuration is used for operational NWP. The ocean configuration (and ocean data assimilation) relies heavily on the existing oceanonly global FOAM.

Modest improvements in coupled forecast skill (particularly in the tropics) compared to uncoupled atmospheric and ocean control experiments have been demonstrated and validation of coupled forecasts for provision of the Copernicus Marine Service forecasts showed improvements in some regions over FOAM (which benefits from higher resolution atmosphere forcing), although differences are relatively small. Given the FOAM and NWP systems are well tuned and have been shown to perform extremely well when compared with international partners (e.g. Ryan et al., 2015), this is encour- 
aging and one would expect significant benefits to be realized as the system matures.

In the configurations currently used, the SST field coupled to the atmosphere is from the top ocean model depth level, which has a thickness of $\sim 1 \mathrm{~m}$ and is coupled hourly. However it is known that net surface-heat fluxes calculated from a $1 \mathrm{~m}$ layer instead of a skin SST can differ by $\sim 10 \mathrm{~W} \mathrm{~m}^{-2}$ (Brunke et al., 2008). A skin SST scheme is being developed to implicitly calculate skin SST and non-solar fluxes within the coupled model. Research is ongoing but the diurnal range in SST in the tropics is significantly improved when validated against satellite data.

Work is also ongoing to include a wave model component within the global coupled model system. There are a number of potentially important wave-atmosphere and wave-ocean interactions, but the initial focus is on the wave-dependent surface roughness seen by the atmosphere model.

\subsection{Ocean data assimilation}

There are a number of different methodologies for data assimilation of varying levels of complexity and computational cost. The ocean forecasting systems at the Met Office use an incremental, first guess at appropriate time (FGAT) threedimensional variational (3-DVar) data assimilation scheme, NEMOVAR (Waters et al., 2015). This has a number of properties that make it suitable for operational use, not least the computational cost, and it produces good quality analyses and forecasts (Ryan et al., 2015). Improvements to this methodology are currently being considered. Ensembles are a useful tool for producing uncertainty estimates in forecasts at various lead times, and can therefore provide useful estimation of the short-range forecast errors required by data assimilation schemes. Pure ensemble-based data assimilation methods can suffer from sampling issues when small numbers of ensemble members are available. As this is likely to be the case for initial implementations of ocean ensemble forecasting systems at the Met Office, we intend to make use of the ensemble information using hybrid 3-DVar-ensemble data assimilation schemes. Initial work to implement the capability for using such a scheme in NEMOVAR has been completed (Weaver et al., 2015). Much work remains to be done though to develop an operational system based on this methodology.

As well as the planned improvements to the underlying data assimilation methodology, other aspects of the data assimilation are also being developed. For instance, data assimilation near the Equator has been shown to induce spurious vertical motions, which can adversely affect the biogeochemistry in coupled physical-biogeochemical models. Schemes to reduce the impact of physical data assimilation on vertical motions have been developed and implemented over the years (Bell et al., 2004; Balmaseda et al., 2007), but these schemes do not completely resolve the problem. Waters et al. (2016) described a new scheme (based on the ideas of Bell et al., 2004), which is shown to further reduce the variability in the spurious vertical velocities induced by physical data assimilation near the Equator. Further work on this scheme, and implementation in the operational forecasting systems, is expected over the next year or two.

New data types often become available and are assessed for their suitability to be assimilated in the forecasting systems. Satellite sea surface salinity (SSS) data from the SMOS and Aquarius satellites were assessed by Martin (2015) by comparing them to outputs of the FOAM system and showed some potential for future assimilation. The impact of assimilating data from animal-borne temperature and salinity sensors was assessed by Carse et al. (2015) and the temperature data from these platforms are now assimilated operationally, with the near-real-time salinity data shown to degrade results. Data from the Sentinel-3 satellite (Donlon et al., 2012a) are expected to become available soon, and preparations for their ingestion into the operational ocean forecasting systems at the Met Office are underway.

Besides the general desire to improve the data assimilation capability, a number of new activities and challenges need to be addressed in the coming years. Data assimilation has (in the ocean forecasting community) been primarily developed for global- or basin-scale applications in forced mode (i.e. the ocean model is not coupled to an atmosphere). The development of coupled ocean-atmosphere systems for short-range forecasting means that assimilation schemes need to adapt to this change. A significant recent step forward has been in the setting up of a prototype weakly coupled atmosphere-landocean-sea-ice data assimilation system described by Lea et al. (2015). The system is termed weakly coupled as the data assimilation schemes for the ocean and atmosphere both take as their initial background state the output from a coupled model and add increments to the coupled model, but do not include any information from the ocean when calculating the increments in the atmosphere, and vice versa. Initial results from a weakly coupled data assimilation system are promising, for example giving reduced SST increments as a result of a better balanced system. The impacts on the forecast skill are presently modest though, and further work is required to tune the system. Ongoing work to assess the future direction of coupled data assimilation includes the calculation of coupled ocean-atmosphere error covariances. This work will inform the decision of whether a fully coupled data assimilation system will be developed, and if so, the design of such a system.

The Met Office shelf-seas configurations have assimilated only SST data up to now. Work is underway to develop the assimilation of altimeter sea level anomaly data and temperature and salinity profile data in these configurations. This requires research into how best to make use of these data types in the presence of tides and a changing vertical coordinate, and how to deal with the sparseness of the data compared to the dominant timescales and space scales. 


\subsection{Quantifying skill}

It is critical for the future utility of ocean forecasting services that there is a focus on quantifying and understanding the skill and uncertainty in ocean forecasting systems. Quantifying skill must include an evaluation of systems and components of systems prior to inclusion in a service (validation) and a continuous evaluation of the outputs of a service in operations (verification). Additionally, the quantification of uncertainty can be included as part of the validation or verification process, and is most robustly done using ensemble methods.

Historically, verification has been approached as a secondary activity, and has often been undertaken with a brief and often basic representation through summary statistics. Increasingly, there is a demand from users for clear information on accuracy, which is relevant to the users' application, as well as a more considered approach as to which statistics are applied and reported. There is also the obvious scientific benefit from the insight that verification provides, and a good understanding of the system skill will drive priorities for model and system development. Focusing on the user aspect of verification will help to ensure that existing users make best use of the data, and give them an understanding of the confidence, which can be placed in the forecasts. Model development priorities should be informed by knowledge of the errors, which have greatest impact on users. Presently, this is generally driven by a largely subjective attempt to understand user needs, but with improved user-driven verification this can become increasingly objective.

Compared to NWP and wave forecasting, the routine verification for ocean forecasts uses a very limited set of metrics, primarily mean and root mean square error (RMSE) and in some cases Pearson correlation coefficient. Whilst providing a useful measure of the overall skill of the forecasts, these statistics can also give a misleading picture in more dynamic situations, especially as model resolutions increase. There is a danger of driving model development inappropriately unless these simpler statistical measures are augmented by more sophisticated and well-posed metrics. The development of these metrics is happening in various guises (see e.g. Divakaran et al., 2015 and Ryan et al., 2015). Lessons can be learnt from the science already done in other communities, particularly atmospheric science, but a significant research effort is needed to apply techniques to the specific nature of the ocean and the needs of the ocean users.

\section{Summary}

Ocean services in support of blue and green growth are available, with forecasting and monitoring of most essential elements of the marine environment developed or developing. These services have evolved to meet a growing range of users needs, and continue to evolve to meet new challenges, for ex- ample to deliver information to the Marine Strategy Framework Directive.

The Met Office has a wide range of applications that are increasingly supporting public and commercial organizations that operate in the marine environment. These services can and will be improved. This paper summarizes the science priorities for driving these improvements. Sciencebased services need to be supported by a balanced research programme. In this case, that means developing not only the underpinning science of the modelling systems and data assimilation but also the inputs to them, including observations and boundary conditions. Coupled modelling provides one means (albeit a costly one) to do this. Methods to initialize analysis and prediction systems will continue to improve, and increasingly probabilistic information will become available to users, improving the utility of the services. Systematic and appropriate evaluation of product skill, in a user focused way, is still in need of considerable research, but must underpin all of the aforementioned activities to ensure that the research activities both lead to scientifically justifiable, as well as known, quantifiable, changes to the products.

Acknowledgements. Funding for the Met Office Ocean Forecasting research activities is gratefully acknowledged from a range of sources, not least from the Public Weather Service, the Ministry of Defence, and the Copernicus Marine Environment Monitoring Service.

Edited by: P.-Y. Le Traon

\section{References}

Allen, J. I., Aiken, J., Anderson, T. R., Buitenhuis, E., Cornell, S., Geider, S. J, Haines, K, Hirata, T., Holt, J., Le Quéré, C., Hardman-Mountford, N., Ross, O. N., Sinha, B., and While, J.: Marine ecosystem models for earth systems applications: the MarQUEST experience, J. Marine Syst., 81, 19-33, 2010.

Ardhuin, F., Rogers, E., Babanin, A. V., Filipot, J.-F., Magne, R., Roland, A., Van der Westhuysen, A., Queffeulou, P., Lefevre, J.M., Aouf, L., and Collard, F.: Semi-empirical dissipation source functions for wind-wave models - Part I: definition, calibration and validation, J. Phys. Oceanogr., 40, 1917-1941, 2010.

Babanin, A. V.: Breaking and Dissipation of Ocean Surface Waves, Cambridge University Press, Cambridge, p. 480, 2011.

Balmaseda, M. A., Dee, D., Vidard, A., and Anderson, D. L. T.: A multivariate treatment of bias for sequential data assimilation: application to the tropical oceans, Q. J. Roy. Meteorol. Soc., 133, 167-179, 2007.

Baxter, P. J.: The east coast Big Flood, 31 January-1 February 1953: a summary of the human disaster, Phil. Trans. R. Soc. A, 363, 1293-1312, 2005.

Belcher, S. E, Grant, A. L. M., Hanley, K. E., Fox-Kemper, B., Van Roekel, L., Sullivan, P. P., Large, W. G., Brown, A., Hines, A., Calvert, D., Rutgersson, A., Pettersson, H., Bidlot, J. R., Janssen, P. A. E. M, and Polton, J. A.: A global per- 
spective on Langmuir turbulence in the ocean surface boundary layer, Geophys. Res. Lett., 39, 1944-8007, 2012.

Bell, M. J., Martin, M. J., and Nichols, N. K.: Assimilation of data into an ocean model with systematic errors near the equator, Q. J. Roy. Meteorol. Soc., 130, 873-893, 2004.

Bidlot, J. R., Janssen, P. A. E. M., and Abdalla, S.: On the importance of spectral wave observations in the continued development of global wave models, in: Proc. 5th International Symposium WAVES, edited by: Edge, B. L. and Santas, J. C., IAHR Secretariat Paper 207, Madrid, Spain, 2005.

Bowler, N., Arribas, A., Mylne, K., Robertson, R., and Beare, S.: The MOGREPS short-range ensemble prediction system, Q. J. Roy. Meteorol. Soc., 134, 703-722, 2008.

Brassington, G. B., Martin, M. J., Tolman, H. L., Akella, S., Balmeseda, M., Chambers, C. R. S., Cummings, J. A., Drillet, Y., Jansen, P. A. E. M., Laloyaux, P., Lea, D., Mehra, A., Mirouze, I., Ritchie, H., Samson, G., Sandery, P. A., Smith, G. C., Suarez, M., and Todling, R.: Progress and challenges in short- to mediumrange coupled prediction, J. Op. Oceanogr., 8, s239-s258, 2015.

Brown, J. and Wolf, J.: Coupled wave and surge modelling for the eastern Irish Sea and.implications for model wind-stress, Cont. Shelf Res., 29, 1329-1342, 2009.

Brunet, G., Shapiro, M., Hoskins, B., Moncrieff, M., Dole, R., Kiladis, G. N., Kirtman, B., Lorenc, A., Mills, B., Morss, R., Polavarapu, S., Rogers, D., Schaake, J., and Shukla, J.: Collaboration of the weather and climate communities to advance subseasonal-to-seasonal prediction, B. Amer. Meteor. Soc., 91, 1397-1406, 2010.

Brunke, M. A., Zeng, X., Misra, V., and Beljaars, A.: Integration of a prognostic skin sea surface temperature scheme into climate and weather models, J. Geophysical Res., 113, D21117, doi:10.1029/2008JD010607, 2008.

Bunney, C. and Saulter, A.: An ensemble forecast system for prediction of Atlantic-UK wind waves, Ocean Model., doi:10.1016/j.ocemod.2015.07.005, online first, 2015.

Carse, F., Martin, M., Sellar, A., and Blockley, E.: Impact of assimilating marine mammal temperature and salinity data on FOAM ocean model fields, Q. J. Roy. Meteorol. Soc., doi:10.1002/qj.2613, online first, 2015.

Cavaleri, L. and Bertotti, L.: The improvement of modelled wind and wave fields with increasing resolution. Tellus, 33, 553-565, 2006.

Conference Statement in Proceedings of OceanObs'09: Sustained Ocean Observations and Information for Society (Vol. 1), Venice, Italy, 21-25 September 2009, edited by: Hall, J., Harrison, D. E., and Stammer, D., ESA Publication WPP-306, doi:10.5270/OceanObs09.Statement, 2010.

Cotter, C. J. and Thuburn, J.: A finite element exterior calculus framework for the rotating shallow-water equations, J. Comp. Physics, 257, 1506-1526, 2014.

Danilov, S.: Ocean modeling on unstructured meshes, Ocean Model., 69, 195-210, 2013.

Deacu, D., Fortin, V., and Klyszejko, E.: Predicting the net basin supply to the Great Lakes with a hydrometeorological model, J. Hydrometeorol., 13, 1739-1759, 2012.

Divakaran, P., Brassington, G. B, Ryan, A. G., Regnier, C., Spindler, T., Mehra, A., Hernandez, F., Smith, G. C., Liu, Y., and Davidson, F.: GODAE OceanView Inter-comparison for the Australian Region, J. Op. Oceanogr., 8, s112-s126, 2015.
Donlon, C., Berruti, B., Buongiorno, A., Ferreira, M.-H., Féménias, P., Frerick, J., Goryl, P., Klein, U., Laur, H., Mavrocordatos, C., Nieke, J., Rebhan, H., Seitz, B., Stroede, J., and Sciarra, R.: The Global Monitoring for Environment and Security (GMES) Sentinel-3 mission, Remote Sens. Environ., 120, 37-57, 2012a.

Donlon, C., Martin, M., Stark, J., Roberts-Jones, J., Fiedler, E., and Wimmer, W.: The Operational Sea Surface Temperature and Sea Ice Analysis (OSTIA) system, Remote Sens. Environ., 116, 140 158, $2012 \mathrm{~b}$.

Drévillon, M., Bourdallé-Badie, R., Derval, C., Drillet, Y., Lellouche, J. M., Rémy, E., Tranchant, B., Benkiran, M., Greiner, E., Guinhut, S., Verbrugge, N., Garric, G., Testut, C. E., Laborie, M., Nouel, L., Bahurel, P., Bricaud, C., Crosnier, L., Dombrowsky, E., Durand, E., Ferry, N., Hernandez, F., Le Galloudec, O., Messal, F., and Parent, L.: The GODAE/MercatorOcéan global ocean forecasting system: results, applications and prospects, J. Op. Oceanogr., 1, 51-57, 2008.

European Centre for Medium-Range Weather Forecasts: Workshop proceedings: ECMWF workshop on ocean waves, available at: http://old.ecmwf.int/publications/library/do/references/ list/201210251 (last access: 21 October 2015), 2012.

Fiedler, E. K., Martin, M. J., and Roberts-Jones, J.: An operational analysis of lake surface water temperature, Tellus A, 66, 21247, doi:10.3402/tellusa.v66.21247, 2014.

Fischer, A. S., Hall, J., Harrison, D. E, Stammer, D., and Benveniste, J.: "Conference Summary-Ocean Information for Society: Sustaining the Benefits, Realizing the Potential" in Proceedings of OceanObs'09: Sustained Ocean Observations and Information for Society (Vol. 1), Venice, Italy, 21-25 September 2009, edited by: Hall, J., Harrison, D. E., and Stammer, D., ESA Publication WPP-306, doi:10.5270/OceanObs09.Summary, 2010.

Flather, R. A.: A Storm Surge Prediction Model for the Northern Bay of Bengal with Application to the Cyclone Disaster in April 1991, J. Phys. Oceanogr., 224, 172-190, 1994.

Flowerdew, J., Horsburgh, K., Wilson, C., and Mylne, K.: Development and evaluation of an ensemble forecasting system for coastal surges, Q. J. Roy. Meteorol. Soc., 136, 1444-1456, 2010.

Gent, P. R. and McWilliams, J. C.: Isopycnal mixing in ocean circulation models, J. Phys. Oceanogr., 20, 150-155, 1990.

Golding, B. W., Ballard, S. P., Mylne, K., Roberts, N., Saulter, A., Wilson, C., Agnew, P., Davis, L. S., Trice, J., Jones, C., Simonin, D., Li, Z., Pierce, C., Bennett, A., Weeks, M., and Moseley, S.: Forecasting capabilities for the London 2012 Olympics, B. Am. Meteorol. Soc., 95, 883-896, 2014.

Hasselmann, S., Hasselmann, K., Allender, J. H., and Barnett, T. P.: Computations andparameterisations of the nonlinear energy transfer in a gravity wave spectrum - Part 2: Parameterisations of the nonlinear energy transfer for application in wave models, J. Phys. Oceanogr., 15, 1378-1391, 1985.

Hyder, P., While, J., Arnold, A., O’Dea, E., Furner, R., Siddorn, J., Martin, M., and Sykes, P.: Evaluating a new NEMO-based Persian/Arabian Gulf tidal operational model, J. Op. Oceanogr., 6, 3-16, 2012.

Janssen, P. A. E. M.: Progress in ocean wave forecasting, J. Comput. Phys., 227, 3572-3594, 2008.

Janssen, P. A. E. M. and Bidlot, J.-R.: On the extension of the freak wave warning system and its verification, ECMWF Technical Memorandum 588, ECMWF, Reading, UK, 2009. 
Janssen, P. A. E. M., Abdalla, S., Hersbach, H., and Bidlot, J.-R.: Error estimation of buoy, satellite, and model wave height data, J. Atmos. Oc. Tech., 24, 1665-1677, doi:10.1175/JTECH2069.1, 2007.

Janssen, P. A. E. M., Breivik, Ø., Mogensen, K., Vitart, F., Balmaseda, M., Bidlot, J.-R., Keeley, S., Leutbecher, M., Magnusson, L., and Molteni, F.: Air-sea interaction and surface waves, ECMWF Technical Memorandum 712, ECMWF, Reading, UK, 2013.

Kim, H.-M., Hoyos, C. D., Webster, P. J., and Kang, I.-S.: Oceanatmosphere coupling and the boreal winter MJO, Clim. Dynam., 35, 771-784, 2010.

King, R. R. and Martin, M.: Comparing satellite altimetry with ocean models of the North-West Shelf Forecasting Research Technical Report No 581, Met Office, Exeter, UK, 2013.

Kohno, N.: An approach for tough navigation sea information, in: Proc. 13th International Workshop on Wave Hindcasting and Forecasting, 27 October- 1 November 2013, Banff, Canada, 2013.

Lea, D., Mirouze, I., Martin, M., King, R., Hines, A., Walters, D., and Thurlow, M.: Assessing a new coupled data assimilation system based on the Met Office coupled atmosphere, land, ocean, sea ice model, Mon. Weather Rev., doi:10.1175/mwr-d15-0174.1, online first, 2015.

Leclair, M. and Madec, G.: z-coordinate, an arbitrary LagrangianEulerian coordinate separating high and low frequency motions, Ocean Model., 37, 139-152, 2011.

Lewis, H., Mittermaier, M., Mylne, K., Norman, K., Scaife, A., Neal, R., Pierce, C., Harrison, D., Jewell, S., Kendon, M., Saunders, R., Brunet, G., Golding, B., Kitchen, M., Davies, P., and Pilling, C.: From months to minutes - exploring the value of high-resolution rainfall observation and prediction during the UK winter storms of 2013/2014, Met. Apps, 22, 90-104, 2015.

Li, J. G.: Upstream non-oscillatory advection schemes, Mon. Weather Rev., 136, 4709-4729, 2008.

Li, J. G.: Global transport on a spherical multiple-cell grid, Mon. Weather Rev., 139, 1536-1555, 2011.

Li, J. G.: Propagation of ocean surface waves on a spherical multiple-cell grid, J. Comput. Phys., 231, 8262-8277, 2012.

Li, J. G. and Saulter, A.: Unified global and regional wave model on a multi-resolution grid, Ocean Dynam., 64, 1657-1670, 2014.

Madec, G.: NEMO ocean engine. Note du Pole de modélisation, Institut Pierre-Simon Laplace (IPSL), France, 27, 1288-1619, 2008.

Martin, M.: Suitability of satellite sea surface salinity data for assessing and correcting ocean forecasts, Forecasting Research Technical Report No. 599, Met Office, Exeter, UK, 2015.

Martin, M., Dash, P., Ignatov, A., Banzon, V., Beggs, H., Brasnett, B., Cayula, J.-F., Cummings, J., Donlon, C., Gentemann, C., Grumbine, R., Ishizaki, S., Maturi, E., Reynolds, R. W., and Roberts-Jones, J.: Group for high resolution sea surface temperature (GHRSST) analysis fields inter-comparisons. Part 1: A GHRSST multi-product ensemble (GMPE), Deep-Sea Res. Pt. II, 77-80, 21-30, 2012.

Merchant, C. J., Embury, O., Roberts-Jones, J., Fiedler, E., Bulgin, C. E., Corlett, G. K., Good, S., McLaren, A., Rayner, N., Morak-Bozzo, S., and Donlon, C.: Sea surface temperature datasets for climate applications from Phase 1 of the European
Space Agency Climate Change Initiative (SST CCI), 1, 2, 179191, 2014.

Niclasen, B. A., Simonsen, K., and Magnusson, A. K.: Wave forecasts and small vessel safety: a review of operational warning parameters, Mar. Struct., 23, 1-21, 2010.

O’Dea, E. J., Arnold, A. K., Edwards, K. P., Furner, R., Hyder, P., Martin, M. J., Siddorn, J. R., Storkey, D., While, J., Holt, J. T., and Liu, H.: An operational ocean forecast system incorporating NEMO and SST data assimilation for the tidally driven European North-West shelf, J. Op. Oceanogr., 5, 3-17, 2012.

O'Neill, C. K., Polton, J. A., Holt, J. T., and O'Dea, E. J.: Modelling temperature and salinity in Liverpool Bay and the Irish Sea: sensitivity to model type and surface forcing, Ocean Sci., 8, 903-913, doi:10.5194/os-8-903-2012, 2012.

Petersen, M. R., Jacobsen, D. W., Ringler, T. D., Hecht, M. W., and Maltrud, M. E.: Evaluation of the arbitrary Lagrangian-Eulerian vertical coordinate method in the MPAS-Ocean model, Ocean Model., 86, 93-113, 2015.

Pietroniro, A., Fortin, V., Kouwen, N., Neal, C., Turcotte, R., Davison, B., Verseghy, D., Soulis, E. D., Caldwell, R., Evora, N., and Pellerin, P.: Development of the MESH modelling system for hydrological ensemble forecasting of the Laurentian Great Lakes at the regional scale, Hydrol. Earth Syst. Sci., 11, 1279-1294, doi:10.5194/hess-11-1279-2007, 2007.

Pinardi, N., Bonazzi, A., Dobricic, S., Milliff, R. F., Wikle, C. K., and Berliner, L. M.: Ocean ensemble forecasting - Part II: Mediterranean Forecast System response, Q. J. Roy. Meteorol. Soc., 137, 879-893, 2011.

Pullen, J., Doyle, J., and Signell, R. P.: Two-way air-sea coupling: a study of the Adriatic, Mon. Weather Rev., 134, 1465-1483, 2006.

Pullen, J., Holt, T., Blumberg, A., and Bornstein, R.: Atmospheric response to local upwelling in the vicinity of New York - New Jersey Harbor, J. Appl. Meteorol., 46, 1031-1052, 2007.

Renault, L., Chiggiaro, J., Warner, J. C., Gomez, M., Vizoso, G., and Tintoré, J.: Coupled atmosphere-ocean-wave simulations of a storm event over the Gulf of Lion and Balearic Sea, J. Geophys. Res., 117, C09019, doi:10.1029/2012JC007924, 2012.

Ringler, T., Petersen, M., Higdon, R. L., Jacobsen, D., Jones, P. W., and Maltrud, M.: A multi-resolution approach to global ocean modeling, Ocean Model., 69, 211-232, 2013.

Roberts-Jones, J., Fiedler, E. K., and Martin, M. J.: Daily, global, high-resolution SST and sea ice reanalysis for 1985-2007 using the OSTIA system, J. Climate, 25, 6215-6232, 2012.

Ryan, A. G., Regnier, C., Divakaran, P., Spindler, T., Mehra, A., Smith, G. C., Davidson, F., Hernandez, F., Maksymczuk, J., and Liu, Y.: GODAE OceanView Class 4 forecast verification framework: global ocean inter-comparison, J. Op. Oceanogr., 8, s98s111, 2015.

Sakov, P., Counillon, F., Bertino, L., Lisæter, K. A., Oke, P. R., and Korablev, A.: TOPAZ4: an ocean-sea ice data assimilation system for the North Atlantic and Arctic, Ocean Sci., 8, 633-656, doi:10.5194/os-8-633-2012, 2012.

Saulter, A.: Assessment of WAM Cycle-4 based source terms for the Met Office global-regional wave modelling system, Forecasting Research Technical Report No 598, Met Office, Exeter, UK, 2015 . 
Savina, H. and Lefevre, J. M.: Sea state in marine safety information: present state, future prospects, in: Rogue Waves 2004, IFREMER, Brest, 2004.

Shapiro, M., Shukla, J., Brunet, G., Nobre, C., Beland, M., Dole, R., Tremberth, K., Anthes, R., Asrar, G., Barrie, L., Bougeault, P., Brasseur, G., Burridge, D., Busalacchi, A., Caughey, J., Chen, D., Church, B., Enomoto, T., Hoskins, B., Hov, Ø., Laing, A., Le Treut, H., Marotzke, J., McBean, G., Meehl, G., Miller, M., Mills, B., Mitchell, J., Moncrieff, M., Nakazawa, T., Olafsson, H., Palmer, T., Parson, D., Rogers, D., Simmons, A., Troccoli, A., Toth, Z., Uccellini, L., Velden, C., and Wallace, J. M.: An Earth-System prediction initiative for the 21st Century, B. Am. Meteorol. Soc., 91, 1377-1388, 2010.

Shelly, A., Xavier, P., Copsey, D., Johns, T., Rodriguez, J. M., Milton, S., and Klingaman, N.: Coupled versus uncoupled hindcast simulations of the Madden-Julian Oscillation in the Year of Tropical Convection, Geophys. Res. Lett., 41, 5670-5677, 2014.

Siddorn, J. R. and Furner, F.: An analytical stretching function that combines the best attributes of geopotential and terrain-following vertical coordinates, Ocean Model., 66, 1-13, 2013.

Siddorn, J. R., Allen, J. I., Blackford, J. C., Gilbert, F. J., Holt, J. T., Holt, M. W., Osborne, J. P., Proctor, R., and Mills, D. K.: Modelling the hydrodynamics and ecosystem of the North-West European continental shelf for operational oceanography, J. Marine Syst., 65, 417-429, 2007.

Smith, G. C., Roy, F., and Brasnett, B.: Evaluation of an operational ice-ocean analysis and forecasting system for the Gulf of St Lawrence, Q. J. R. Meteorol. Soc., 139, 419-433, 2013.

Storkey, D., Blockley, E. W., Furner, R., Guiavarc'h, C., Lea, D., Martin, M. J., Barciela, R. M., Hines, A., Hyder, P., and Siddorn, J. R.: Forecasting the ocean state using NEMO: the new FOAM system, J. Op. Oceanogr., 3, 3-15, 2010.

Tappin, D., Sibley, A., Horsburgh, K., Daubord, C., Cox, D., and Long, D.: The English Channel tsunami of 27 June 2011 a probable meteorological source, Weather, 68, 144-152, 2013.

Thuburn, J. and Cotter, C. J.: A primal-dual mimetic finite element scheme for the rotating shallow water equations on polygonal spherical meshes, J. Comput. Phys., 290, 274-297, 2015.

Tolman, H. L.: User manual and system documentation of WAVEWATCH III $^{\mathrm{TM}}$ version 3.14. NOAA/NWS/NCEP/MMAB Technical Note 276, 194 pp. + Appendices, Silver Spring, Maryland, USA, 2009
Tolman, H. L.: A Generalized Multiple Discrete Interaction Approximation for resonant four-wave nonlinear interactions in wind wave models with arbitrary depth, Ocean Modelling, 70, 11-24, 2012.

Tolman, H. L.: User manual and system documentation of WAVEWATCH III version 4.18. NOAA/NWS/NCEP/MMAB Technical Note 316, 194 pp. + Appendices, Silver Spring, Maryland, USA, 2014.

Tolman, H. L., Banner, M. L., and Kaihatu, J. M.: The NOPP operational wave model improvement project, Ocean Model., 70, 2-10, 2013.

Warner, J. C., Armstrong, B., He, R., and Zambon, J. B.: Development of a coupled ocean-atmosphere-wave-sediment transport (COAWST) modelling system, Ocean Model., 35, 230-244, 2010.

Waters, J., Lea, D. J., Martin, M. J., Mirouze, I., Weaver, A., and While, J.: Implementing a variational data assimilation system in an operational 1/4 degree global ocean model, Q. J. R. Meteorol. Soc., 141, 333-349, 2015.

Waters, J., Bell, M. J., and Martin, M. J.: Reducing ocean model imbalances in the equatorial region caused by data assimilation, Q. J. R. Meteorol. Soc., submitted, 2016.

Weaver, A. T., Tshimanga, J., and Piacentini, A.: Correlation operators based on an implicitly formulated diffusion equation solved with the Chebyshev iteration, Q. J. R. Meteorol. Soc., doi:10.1002/qj.2664, online first, 2015.

Williams, K. D., Harris, C. M., Bodas-Salcedo, A., Camp, J., Comer, R. E., Copsey, D., Fereday, D., Graham, T., Hill, R., Hinton, T., Hyder, P., Ineson, S., Masato, G., Milton, S. F., Roberts, M. J., Rowell, D. P., Sanchez, C., Shelly, A., Sinha, B., Walters, D. N., West, A., Woollings, T., and Xavier, P. K. The Met Office Global Coupled model 2.0 (GC2) configuration, Geosci. Model Dev., 8, 1509-1524, doi:10.5194/gmd-8-15092015, 2015.

WISE Group: Wave modelling - the state of the art, Prog. Oceanogr., 75, 603-674, 2007. 